\title{
REFINED GENERALIZATIONS OF THE TRIANGLE INEQUALITY ON BANACH SPACES
}

\author{
Sin-Ei TAKahasi, John M. Rassias, SABUrou SAITOH \\ AND YASUJI TAKAHASHI
}

Abstract. Let $X$ be a complex Banach space and $p$ a real number with $p \geqslant 1$. We give a necessary and sufficient condition for complex numbers $a, b$ and real numbers $\lambda, \mu$ and $v$ in order that the inequality

$$
\frac{\|a x+b y\|^{p}}{\lambda} \leqslant \frac{\|x\|^{p}}{\mu}+\frac{\|y\|^{p}}{v}
$$

holds for every $x, y \in X$.

Mathematics subject classification (2010): 26D15, 26D20.

Keywords and phrases: Inequalities, triangle inequalities, Banach space, Euler-Lagrange type identity, Hua's inequality.

\section{REFERENCES}

[1] BoHR, H., Zur theorie der fastperiodischen funktionen I, Acta Math. 45 (1924) 29-127.

[2] Cheung, W.-S. AND PeČARIĆ, J., Bohr's inequalities for Hilbert space operators, J. Math. Anal. Appl. 323 (2006), 403-412.

[3] Niculescu, C., And Persson, L.-E., Convex Functions and Their Applications - A Contemporary Approach, CMS Press, Springer 2006.

[4] PEČARIĆ, J. AND RASSIAS, TH. M., Variations and generalizations of Bohr's inequality, J. Math. Anal. Appl. 174 (1993), 138-146.

[5] RASSIAS, J. M., On the stability of the Euler-Lagrange functional equation, Chinese J. Math. 20(1992), $185-190$.

[6] RASSIAS, J. M., On the stability of the non-linear Euler-Lagrange functional equation in real normed linear spaces, J. Math. Phys. Sci. 28(1994), 231-235.

[7] RASSIAS, J. M., On the stability of the general Euler-Lagrange functional equation, Demonstratio Math. 29(1996), 755-766.

[8] RASSIAS, J. M., Solutions of the Ulam stability problem for Euler-Langrage quadratic mappings, J. Math. Anal. Appl. 220(1998), 613-639.

[9] RASSIAS, J. M., On the stability of the muti-dimensional Euler-Laglange functional equation, J. Indian Math. Soc. (N.S.), 66(1999), 1-9.

[10] RASSIAS, J. M., AND RASSIAS, M. J., On the Ulam stability for Euler-Lagrange type quadratic functional equations, Austral. J. Anal. Appl. 2(2005), 1-10.

[11] SAITOH, S., Various operators in Hilbert space introduced by transforms, International J. of Applied Math. 1(1999), no. 1, 111-126.

[12] SAIтoH, S., Generalizations of the triangle inequality, J. Inequal. Pure Appl. Math. 4(2003), no. 3, Article 62, 1-5.

[13] TAKagi, H., Miura, T., Hayata, T., AND TAKahasi, S.-E., A reconsideration of Hua's inequality II, J. Inequal. Appl. (to appear). 